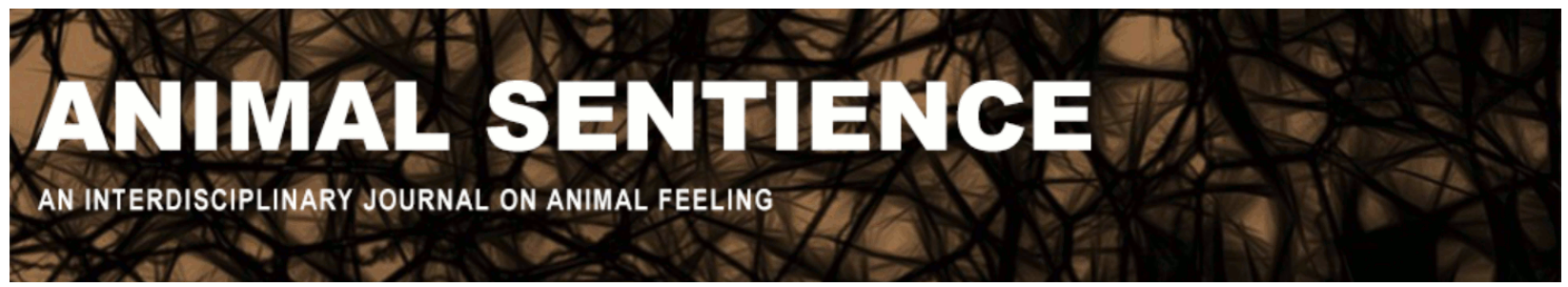

Cheng, Tony (2016) Why animals are persons. Animal Sentience 10(4) DOI: $10.51291 / 2377-7478.1128$

Date of submission: 2016-07-23

Date of acceptance: 2016-07-26

(c) (i)




\title{
Why animals are persons
}

Commentary on Rowlands on Animal Personhood

\author{
Tony Cheng \\ Department of Philosophy \\ University College, London
}

\begin{abstract}
Rowlands's case for attributing personhood to lower animals is ultimately convincing, but along the way he fails to highlight several distinctions that are crucial for his argument: Personhood vs. personal identity; the first person vs. its mental episodes; and prereflective awareness in general vs. one specific case of it.
\end{abstract}

Tony Cheng is a PhD candidate in philosophy at University College, London. His research is on the relation between object cognition and spatial representation. http://philpapers.org/profile/91700

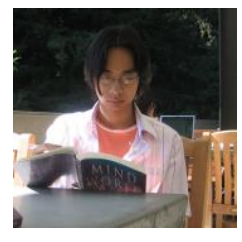

In the target article, Mark Rowlands (2016) makes a convincing case for the idea that many non-human animals are persons in the metaphysical sense. He starts with the Lockean definition because "discussion [in this literature] is often based on a certain conception of what these person-conferring features would have to be ... [and this] conception derives (knowingly or unknowingly) from John Locke's famous definition of a person...." Rowlands's strategy is to accept the Lockean definition, but to understand it in terms of his notion of "pre-reflective awareness" so as to have a more sensible view of what a person is and thereby attribute personhood to far more non-human animals. Although his line here is in general plausible, certain key distinctions are missed in his argument. In what follows I discuss three of them.

First, there is a distinction between personhood and personal identity. The former concerns what counts as a person, while the latter focuses on the identity and persisting conditions of being a person. These are certainly connected, but one needs to be clear about what is at issue exactly. As Olson (2008) observes, philosophers tend to focus exclusively on the survival conditions over time and therefore omit other important issues:

"Claims about what it takes for us to persist do not by themselves tell us what other fundamental properties we have: whether we are material or immaterial, simple or composite, abstract or concrete, and so on. At any rate, the single-minded focus on our identity over time has tended to put other metaphysical questions about ourselves out of philosophers' minds." (Olson 2008, p. 352)

Locke's definition is primarily designed to deal with personal identity. That is why it emphasises the temporal dimension ("in different times"). But what is at issue is personhood. Moreover, what Locke had in mind was primarily human persons, as one can see from his demanding definition. It is unclear why Rowlands would want to start with this definition: although he writes that in the literature this is often the case, he does not cite specific 
examples. I would rather start with the personal/sub-personal distinction, as it is more up to date and relevant to the current discussion of animals and persons (e.g., Bermúdez 2005, Drayson 2012).

The second distinction is between the first person and its mental episodes. In this judgment that "I am in pain," "I" is the first person while "pain" is the mental episode in question. When theorists use the term "self-awareness," they can mean either the former or the latter. When Rowlands discusses the difference between awareness of the book being on the table and awareness of being in pain, what he has in mind is self-awareness in relation to mental episodes, since what is at issue is pain, not the self. But he soon turns to self-awareness in relation to the first person when he discusses immunity to error through misidentification and related issues (Shoemaker 1968). This makes it unclear what is at issue. To be sure, the two kinds of awareness are related in complicated ways, but one must be clear about what the target of awareness is: the first person or its mental episodes.

The third distinction is between pre-reflective awareness in general and one specific version of it. What is reflective awareness in the relevant sense? Rowlands explains this in section 2 with the intentional model, which fits nicely with the standard reading of the Lockean model. Pre-reflective awareness, as Rowlands intends it, is borrowed from Sartre. Because it is pre-reflective, it is able to accommodate the case of non-human animals, which involves no linguistic and perhaps no conceptual capacity. Rowlands substantiates his notion of pre-reflective awareness as follows: "My being in pain is not independent of my awareness of being in pain." This is a strong claim in philosophy of mind; for example, it is a denial of every version of higher-order theory of consciousness (Armstrong 1968, Rosenthal 1986, Carruthers 1996, Lycan 1996). More generally, it is a denial of the appearance/reality distinction in the realm of the mental. It might be correct ultimately, but it requires further arguments. It is much more specific than insisting on the existence of pre-reflective awareness. Rowlands does mention higher-order theories, but without substantive discussion. Although his case for pre-reflective awareness is convincing, the further denial of the distinction between mental appearance and reality seems unwarranted.

\section{References}

Armstrong, D. (1968). A materialist theory of the mind. London: Routledge.

Bermúdez, J. L. (2005). Philosophy of psychology: a contemporary introduction. New York: Routledge.

Carruthers, P. (1996). Language, thought, and consciousness. Cambridge: Cambridge University Press.

Drayson, Z. (2012). The uses and abuses of the personal/subpersonal distinction. Philosophical perspectives, 26(1), 1-18.

Lycan, W. (1996). Consciousness and experience. Cambridge, MA: MIT Press.

Olson, E. (2008). An argument for animalism. In P. van Inwagen and D. W. Zimmerman (Eds.), Metaphysics: the big questions, $2^{\text {nd }}$ edition. Blackwell Publishing.

Rosenthal, D. (1968). Two concepts of consciousness. Philosophical Studies, 49, 329-359.

Rowlands, M. (2016). Are animals persons? Animal Sentience 2016.101.

Shoemaker, S. (1968). Self-reference and self-awareness. The Journal of Philosophy, 65(19), 555-567. 